\title{
Individual placement and support led to more competitive employment than did enhanced vocational rehabilitation for severe mental disorder
}

Drake RE, McHugo GJ, Bebout RR, et al.A randomized clinical trial of supported employment for inner-city patients with severe mental disorders. Arch Gen Psychiatry 1999 Jul;56:627-33.

QUESTION: In people with severe mental disorder (SMD), is individual placement and support (IPS) better than enhanced vocational rehabilitation (EVR) for increasing competitive employment?

Design

Randomised (unclear allocation concealment*), unblinded*, controlled trial with 18 months of follow up.

Setting

A community agency in southeast Washington, DC, USA.

\section{Patients}

152 unemployed, inner city patients (mean age $39 \mathrm{y}$, $61 \%$ women, $83 \%$ African-American) who had SMD (schizophrenia spectrum 67\%, bipolar disorder 14\%, depressive disorders $16 \%$, other Axis I disorder 3\%) and no memory impairment or illness that would affect participation in study. Patients were recruited from an agency that serves patients with SMD who need intensive case management. Follow up was $99 \%$ at 18 months for vocational outcomes.

\section{Intervention}

After stratification for work history, patients were allocated to IPS $(n=76)$ or EVR $(n=76)$. In the IPS group, 3 employment specialists helped clients to search rapidly for jobs and provided individualised follow up once clients were employed. IPS was implemented according to a manual. EVR consisted of vocational rehabilitation services provided by community agencies with the support of an additional vocational counsellor who ensured that patients in the EVR group received expeditious referral to appropriate services.

Main outcome measures

Competitive employment and sheltered employment.

\section{Main results}

Sources of funding: Substance Abuse and Mental Health Services Administration and

National Institute of

Mental Health.

For correspondence: $\mathrm{Dr}$ R E Drake, Psychiatric Research Center, 2

Whipple Place,

Lebanon, $N H 03766$,

USA. Fax +1603448

0129 .
At 18 months, IPS led to more participants finding competitive jobs $(\mathrm{p}<0.001)$ and to fewer participants working in sheltered employment $(\mathrm{p}<0.001)$ than did EVR (table).

\section{Conclusion}

In people with severe mental disorder, individual placement and support led to greater success at finding competitive employment than did enhanced vocational rehabilitation.

*See glossary.
Individual placement and support (IPS) v enhanced vocation rehabilitation (EVR) for severe mental disordert

\begin{tabular}{|c|c|c|c|c|}
\hline $\begin{array}{l}\text { Outcomes at } \\
18 \text { months }\end{array}$ & IPS & EVR & $\begin{array}{l}\text { RBI } \\
(95 \% \mathrm{Cl})\end{array}$ & $\begin{array}{l}\text { NNT } \\
(\mathrm{Cl})\end{array}$ \\
\hline $\begin{array}{l}\text { Any competitive } \\
\text { job }\end{array}$ & $61 \%$ & $9 \%$ & $\begin{array}{l}560 \% \\
\text { (232 to } 1269)\end{array}$ & $\begin{array}{l}2 \\
\text { (2 to } 3 \text { ) }\end{array}$ \\
\hline & & & $\begin{array}{l}\text { RRR } \\
(\mathrm{Cl})\end{array}$ & $\begin{array}{l}\text { NNT } \\
\text { (Cl) }\end{array}$ \\
\hline Any sheltered jok & $11 \%$ & $71 \%$ & $\begin{array}{l}85 \% \\
\text { ( } 71 \text { to } 92)\end{array}$ & $\begin{array}{l}2 \\
\text { (2 to } 3)\end{array}$ \\
\hline
\end{tabular}

†Abbreviations defined in glossary; RBI, RRR, NNT, and $\mathrm{Cl}$ calculated from data in article.

\section{COMMENTARY}

The study by Drake $e t a l$, which could prove to be of substantive value to the community of rehabilitation professionals working with clients with SMD, addresses specifically the optimal approach for preparing clients for work.

The study, with a sample of 152 unemployed people living within a large urban centre, addresses an important question relative to work entry or return: should clients with SMD be encouraged to enter the competitive workforce or should they begin their work re-entry through sheltered work settings? At the final point of follow up (18 months), members of the IPS group were more often to be found in competitive employment settings than their colleagues enrolled in EVR, who were placed more often within sheltered settings. This finding, in and of itself, shows the belief of many mental health clinicians, particularly occupational therapists, that attempting to optimise normalisation opportunities for vocational re-entry with clients with SMD is both achievable and desirable.

Not only were direct vocational outcomes influenced positively but other outcome measures, including perceptions of quality of life and self esteem, were markedly enhanced also. Of special interest is the finding that clients within the IPS group reported being more satisfied with the services they received than those in the EVR group. Without a doubt, client satisfaction is a critical component of success and would appear to have a direct link to the personal nature of the intervention for the IPS group. Although client satisfaction alone remains an important, but not sufficient, measure of positive outcome, it should be considered most seriously when coupled with evidence of increased incidence of competitive employment.

This is an important study, which provides not only clearly articulated findings but also suggests a model and directions for further inquiry.

Sue E Baptiste, MHSc OT(C) McMaster University

Hamilton, Ontario, Canada 